\title{
Exploratory factor analysis of the Indonesian version of MMPI-2- RF Restructured Clinical (RC) Scales
}

\author{
Widhi Adhiatma ${ }^{1}$, Magdalena S. Halim ${ }^{2}$ \\ ${ }^{1,2}$ Faculty of Psychology, Universitas Katolik Indonesia Atma Jaya, Indonesia \\ ${ }^{1}$ widhi.adhiatma@atmajaya.ac.id, ${ }^{2}$ magdalena.halim@atmajaya.ac.id
}

ARTICLE INFO

Article history

Received 28 March 2018

Revised 28 March 2019

Accepted 31 March 2019

Keywords

exploratory factor analysis (EFA)

MMPI-2-RF

Restructured Clinical Scales

\begin{abstract}
The Minnesota Multiphasic Personality Inventory (MMPI) is the world's most frequently used scale, both in clinical assessment and psychiatric setting. This measure has been revised several times with MMPI-2-RF (Restructured Form) being the latest version. The Restructured Clinical (RC) Scales, which contains nine sub-scales, is the primary clinical scale in MMPI-2-RF. This scale replaces the Clinical Scales from the previous version of MMPI. This research aimed to analyze the construct validity of the RC Scales using Exploratory Factor Analysis (EFA) technique. The sample of this research involved 279 participants $($ male $=26.5 \%$; female $=73.5 \%)$ with an average of 21.63 years old. The obtained data was analyzed using EFA through Principal Component Analysis (PCA). Results showed that Restructured Clinical Scales consisted of one factor solution, namely psychological disorder. The number of the factors, as well as the structure, was different from the US version of MMPI2-RF Restructured Clinical Scales. Through these findings, MMPI2-RF users in Indonesia are expected to be more cautious when interpreting the Restructured Clinical Scales sub-scales score.
\end{abstract}

\section{Introduction}

The Minnesota Multiphasic Personality Inventory (MMPI) is a personality measurement tool that is most often used in the scope of clinical and psychiatric assessments (Van Der Heijden, Egger, \& Derksen, 2010). Various researchers from several countries are trying to adapt the MMPI test kits into their respective languages, including in Indonesian. Different studies show that the Indonesian version of MMPI-2 has been proven valid and can be used in Indonesian context (Ayuningtyas, 2004; Halim, 2004; Harkuspi, 2004; Nastasya, 2004; Yuliani, 2004).

Even so, the criticism of MMPI-2 is considerably hefty, especially towards the Clinical Scales. This scale is judged as having psychometric drawbacks, precisely the existence of a high level of inter-correlation between sub-scales which weakens convergent and discriminant validity, and the emergence of heterogeneity in one sub-scale, i.e., in one sub-scale there are contents from various syndromes (Tellegen \& Ben-Porath, 2008). Due to these criticisms, a revised version of MMPI-2, MMPI-2-RF was developed in 2008 by making significant changes to almost all MMPI-2 scales and sub-scales, despite the items on MMPI-2-RF coming from an aggregate of MMPI-2 (Tellegen \& Ben-Porath, 2008). In Indonesia, the MMPI-2-RF adaptation process has begun with the testing of validity and 
reliability. The initial psychometric analysis performed on MMPI-2-RF concluded that this measure had a good internal and external validity index as well as good reliability index, thus could be considered as an alternative to MMPI-2. However, carrying out a more complex psychometric test, one of which is factor analysis, is essential to ensure that the measurement can function more optimally as a diagnostic tool (Halim, 2012).

In MMPI-2-RF, the role of Clinical Scales is replaced by Restructured Clinical (RC) Scales (Ingram, Kelso, \& McCord, 2011). The RC Scales is constructed based on the Clinical Scales in MMPI-2. This fixes several of the psychometric drawbacks that exist in the Clinical Scales. Therefore, RC Scales is considered to have better validity and reliability than the Clinical Scales (Simms, Casillas, Clark, Watson, \& Doebbeling, 2005).

RC Scales consists of nine sub-scales (Tellegen \& Ben-Porath, 2008). The first scale is Demoralization ( $\mathrm{RCd})$, which measures an individual's sense of dissatisfaction or general unhappiness. The second scale is Somatic Complaints (RC1), which measures complaints about overall physical health. The third scale is Low Positive Emotions (RC2), which measures the vulnerability factor to depression. The fourth scale is Cynicism (RC3), which measures the extent to which a person believes other people are evil and cannot be trusted, though this belief does not apply to oneself. The fifth scale is Antisocial Behavior (RC4), which measures the tendency to behave unlawfully and irresponsibly. The sixth scale is Ideas of Persecution (RC6), which measures the belief that others pose a threat to themselves. The seventh scale is Dysfunctional Negative Emotions (RC7), which measures the presence of anxiety or the tendency for adaptive irritability. The eighth scale is Aberrant Experiences (RC8), which measures the presence of perceptions or thoughts that are unusual and related to the occurrence of psychosis. The ninth scale is Hypomanic Activation (RC9), which measures the existence of excessive activation, such as aggression, impulsivity, and a sense of 'greatness' or grandiosity.

In its development, several psychometric tests were carried out on the RC Scales in the original MMPI-2 version. When a factor analysis was performed on the RC Scales, it was found that there were five factor solutions (Hoelzle \& Meyer, 2008). The first factor which contains sub-scales RC4 and RC9 reflected maladaptive behavior that has an externalizing nature. The second factor which contains sub-scales RC2 and RCd includes depressive nuances of emotional problems. The third factor reflects psychological problems which take the form of physical complaints measured from $\mathrm{RC} 1$. The fourth factor consists of the sub-scales RC6 and RC8 and describes several symptoms and experiences related to psychosis. The final factor illustrates a person's tendency to be cynical and distrustful of others, which is measured by sub-scale RC3.

During the development of MMPI-2-RF in the United States, factor analysis of RC Scales showed different results. Three factors underlie the nine sub-scales in RC Scales (Tellegen \& Ben-Porath, 2008). The first factor is Emotional/Internalizing Dysfunction (EID), which consists of $\mathrm{RCd}, \mathrm{RC} 1, \mathrm{RC} 2$, and RC7. The second factor is Thought Dysfunction (THD), which consists of RC3, RC6, and RC8. The third factor is Behavioral/Externalizing Dysfunction (BXD), which consists of RC4 and RC9.

In localizing a measurement tool from one country to another, prior psychometric testing is essential. One necessary psychometric testing procedure is factor analysis. Factor analysis technique enables identification of the presence or absence of differences in the meaning of a construct between one culture to another. This difference can be reflected in the structure or number of factors produced (International Test Commission, 2016). Unfortunately, research to determine the factor structure of the Indonesian version of the MMPI-2-RF RC Scales has not been done. As the main clinical scale in MMPI-2-RF, it is essential to understand the meaning of RC Scales in the Indonesian context. 
To answer this problem, this study conducted a construct validity test on the primary clinical scale of MMPI-2-RF, that is RC Scales. The construct validity test in this study was carried out using the factor analysis method, namely through the Exploratory Factor Analysis (EFA) technique. Through the EFA technique, the meaning of RC Scales in Indonesian context can be identified, which, given the differences in the number as well as factor structure between the Indonesian version of MMPI-2-RF and the original version is very likely to be found. Also, by knowing the factor structure of the RC Scales sub-scales, clinics will have an easier time interpreting the scores of RC Scales.

\section{Method}

\section{Participants}

A total of 279 people $($ male $=26.5 \%$; female $=73.5 \%$ ) participated in this study, which consisted of 184 participants from the primary data and 95 participants from the secondary data. Primary data is defined as new or first-hand data collected for this study, while secondary data is data collected from research previously conducted by (Halim, 2012). Assignment of participants was done through convenience sampling technique. To be precise, participants were selected based on the convenience of researchers in accessing participants (Howitt \& Cramer, 2011). Participants were recruited through the relations or network of the researchers. Participants who were willing to participate are gathered in one room according to their time availability. Data collection was carried out in three provinces, namely DKI Jakarta (27.72\%), East Java (63.04\%), and East Nusa Tenggara (9.24\%). Specifically, for data collection in East Nusa Tenggara, assistants with medical education backgrounds were recruited to assist in the data collection. Before carrying out the data collection, the assistant was given an explanation in advance regarding the MMPI2-RF administration procedure.

All participants in this study came from what is considered as the normal population, or individuals who were not diagnosed with any mental disorders. This is in line with the development of MMPI-2-RF in the United States which also uses a normal population. Participants must also meet the minimum age criteria, which is 18 years, and a minimum level of education, which is junior high level (Ben-Porath \& Tellegen, 2018). In this study, the majority of participants were female $(73.5 \%)$. The average age of participants was 21.63 years $(\mathrm{SD}=5.05)$ with the majority having received 8-12 years of education or having completed high school education $(75.6 \%)$.

\section{Procedure}

Data collection was done by administering MMPI-2-RF to participants in a classical manner. All participants had expressed their willingness to take part voluntarily in this study by filling in the consent sheet. After the data was collected, invalid participants determined based on the Validity Scales were excluded. A participant's data was declared invalid if there were more than 14 empty items (CNS>14) and the participant's raw scores on three Validity Scales were above or below a specific cutoff (VRIN-r $>9$, TRIN-r $<7$ or TRIN-r > 15, and Fr > 17). When a criterion is not met, the data will be immediately excluded (Ben-Porath \& Tellegen, 2008). 


\section{Instruments}

The measurement instrument used in this study was the Indonesian version of MMPI-2RF. MMPI-2-RF consists of 338 items which take the form of statements. Participants were asked to assess each statement regarding whether the statement describes his or her self by choosing between True $(\mathrm{T})$ or False $(\mathrm{F})$. The Indonesian version of RC Scales on the MMPI-2-RF version shows adequate reliability (normative sample: $\alpha=.73$ for men, $\alpha$ $=.74$ for women) and has a reasonably good convergent and discriminant validity (Halim, 2012)

\section{Data Analysis}

The analysis technique used in this study was factor analysis using exploratory factor analysis (EFA) technique. The EFA method was chosen as we sought to compare the factor structure between the Indonesian version of MMPI-2-RF and the US version of MMPI-2RF. Through EFA, enables us to discover the higher contributing factor among the existing variables (Cohen \& Swerdlik, 2018), in this case, the RC Scales. Two assumptions in the utilization of EFA that were tested in this study. These assumptions were that the number of samples must be sufficient, and no correlation was too high between facets. These assumptions were measured using the KMO index regarding sample adequacy (minimum value of .5) and Bartlett's test of significance (significant at LOS = .005) (Fields, 2009). After the two assumptions were fulfilled, the next step was to determine the number of factors extracted and rotated. Extraction was based on eigenvalue score (more than 1.0), while the rotation technique used was orthogonal with the varimax method. The principal component analysis (PCA) one of EFA technique was used to analyze the data.

\section{Results}

The test results show that both EFA assumptions were met. The KMO score is .863, and the Bartlett's test shows a significant score (sig <.05). EFA results from the Indonesian language version of MMPI-2-RF RC Scales can be seen in Table 1.

Table 1

EFA results of the Indonesian version of MMPI-2-RF RC Scales

\begin{tabular}{ccc}
\hline \multirow{2}{*}{ Sub-scales of RC Scales } & \multicolumn{2}{c}{ Factor } \\
\cline { 2 - 3 } & \multicolumn{1}{c}{1} & 2 \\
RCd & $\frac{.75}{.65}$ & .47 \\
RC1 & .19 \\
RC2 & -.01 & .93 \\
RC4 & $\underline{.73}$ & .03 \\
RC6 & $\underline{.65}$ & -.02 \\
RC7 & $\underline{.79}$ & -.12 \\
RC8 & $\underline{.87}$ & .15 \\
RC9 & $\frac{.82}{.76}$ & -.14 \\
\hline Note: Numbers in bold have a significant factor loading $(>.4)$. Numbers in bold and underscored have the highest factor loading.
\end{tabular}


Based on Table 1, the factor analysis carried out on nine RC Scales sub-scales produces two factor solutions. When seen from the biggest loading factor, the first factor consists of $\mathrm{RCd}, \mathrm{RC} 1, \mathrm{RC} 3, \mathrm{RC} 4, \mathrm{RC} 6, \mathrm{RC} 7, \mathrm{RC} 8$, and $\mathrm{RC}$, while the second factor consists only of RC2. It is also evident that there are two sub-scales which have a significant factor loading on both factors: sub-scales RCd and RC9. Even so, the two factors are included in the first factor due to having greater factor loading for this first factor. Based on psychometry, the second factor can be ignored as it only contains one sub-scale (RC2). Hence the EFA on the sub-scales of RC Scales produce a one factor solution. Based on the composition of each factor, the first factor is then named Psychological Disorders.

\section{Discussion}

The testing of construct validity using EFA showed that the nine sub-scales of RC Scales are composed of one factor solution. The findings in this study are very different from the factor analysis in the US version of MMPI-2-RF which produces three factor solutions. These three factors are Emotional/Internalizing Dysfunction (EID), Thought Dysfunction (THD), and Behavioral/Externalizing Dysfunction (BXD) (Tellegen \& Ben-Porath, 2008).

Table 2

EFA results of the US version of MMPI-2-RF RC Scales

\begin{tabular}{cccc}
\hline \multirow{2}{*}{ Sub-scales of RC Scales } & \multicolumn{3}{c}{ Factor } \\
\cline { 2 - 4 } & EID & THD & BXD \\
\hline RCd & $\underline{.85}$ & .26 & .33 \\
RC1 & $\underline{.46}$ & .45 & .12 \\
RC2 & $\underline{.86}$ & .09 & -.08 \\
RC3 & .20 & .47 & .41 \\
RC4 & .19 & .18 & .51 \\
RC6 & .13 & .66 & .21 \\
RC7 & .55 & .53 & .47 \\
RC8 & .18 & .79 & .30 \\
RC9 & -.10 & .32 & .92 \\
\hline
\end{tabular}

Source: (Tellegen \& Ben-Porath, 2008)

Note: Numbers in bold have a significant factor loading (>.4). Numbers in bold and underscored have the highest factor loading.

The factor structure found in the United States version of the MMPI-2-RF RC Scales shows a higher structure in mental disorders, namely the presence of disorders that dominate the feeling, thought, and behavior structures. This model is in accordance with the Abnormal Psychology perspective which states that the aforementioned three general structures will be disrupted when a person experiences mental disorders (APA, 2013; Hoeksema, 2014).

The difference in factor structure found in the MMPI-2-RF RC Scales shows a different meaning for mental disorders from the United States context. This is in accordance with the emic perspective, i.e., a person's behavior, thoughts, or emotions need to be seen based on the individual's cultural context (Pomerantz, 2016). In this study, Psychological Disorders factor indicates, that in general, almost all of the sub-scales RC Scales contains contents regarding feeling, thought, and behavior structures. This can be seen from the eight sub-scales of RC Scales converged in the Psychological Disorders factor.

We hypothesizes that this meaning is inseparable from the cultural values embraced by Indonesians. In the context of Javanese culture, the largest cultural group in Indonesia, 
shame is a very significant construct in the dynamics of social interaction (Subandi \& Good, 2018). These feelings are internalized in various social situations. The emotion shame is triggered when someone displays actions that are deemed inappropriate according to the norms of the environment. This has a negative impact on psychopathology, where people who show 'abnormal' actions will be seen as having mental disorders and will, in turn, bring shame to the victim and their family. In this context, it can be seen that psychiatric or psychopathological disorders are interpreted as a unit; that is, people who display 'abnormal' actions. With that being said, in the context of Indonesian culture, the meaning of mental disorders from the three structures of psychiatric disorders becomes less prominent.

These findings indicate that the items on the MMPI-2-RF RC Scales have difficulty in identifying psychopathology, particularly based on these three structures. However, this also affirms the view that often, the manifestation of a psychological syndrome is not only limited to one structure, but a number of structures where both feelings, thoughts, and behaviors, can be affected when a person experiences psychopathology (Agus, 2009).

Even though the EFA results show that there is only one factor solution, the findings in the second factor are still essential to discuss. The sub-scale included in the second factor is RC2. In addition, there are also two sub-scales which have a significant factor loading in this factor, namely RCd and RC9. The structure of the second factor displays structural differences with the US version of RC Scales. In the US version of RC Scales, factors with emotional nuances specifically appear in the RCd, RC1, RC2, RC7 subscales. By looking at the factor structure, the Indonesian version of RC Scales tends to measure mood than emotions itself.

The differences in the factor structure of the RC Scales between the Indonesian and US versions of MMPI-2-RF may influenced by differences in sample characteristics, in addition to the cultural context factors. Development of MMPI-2-RF in the United States uses very diverse sample characteristics, such as normal populations, veteran groups, or clinical patients (Tellegen \& Ben-Porath, 2008). When used in a group of clinical patients, RC Scales shows a better psychometric properties, specifically a reliability index, than when administered to a normal population (Simms et al., 2005). This indicates that RC Scales operates differently when administered to two different groups. In this study, the sample was limited to the normal population group. This also contributes to the differences in the factor structure that emerged in this study.

This study has implications for the use of the Indonesian version of MMPI-2-RF. Based on the existing factor structure, users need to be more careful in interpreting the scores on the subscales of RC Scales, specifically the RCd, RC1, RC3, RC4, RC6, RC7, $\mathrm{RC}$, and RC9. When a person has a high score on one of these sub-scales, the user (psychiatrist or clinical psychologist) must understand that the person is very likely to have problems in the structure of feelings, thoughts, and behavior. This is different from the US version of MMPI-2-RF RC Scales, which is better able to classify a subscale on a psychological structure. In any case, where the user is in need to know which psychiatric structure is problematic, we recommends direct use of MMPI-2-RF H-O (Higher-Order) Scales which measures dysfunctional structures relative to RC Scales. Meanwhile, it must be emphasized that the meaning of the RC2 sub-scale tends to lean towards mood disorders (particularly towards negative moods) than emotions in general.

This research itself still has several limitations. First, the characteristics of the sample are very limited; that is, the normal population group. As previously explained, this minimal sample characteristic is thought to influence the results of the study. Second, the existence of one factor that only contains one variable (RC2) may cause problems, especially when trying to test the equivalence of factors (e.g., through confirmatory factor analysis). Based 
on previous research (Hoelzle \& Meyer, 2008), we suspect this is due to the number of variables used in this study were too small for EFA (nine variables).

\section{Conclusion}

Based on these findings, it can be concluded that there is one factor that underlies the subscales of the Indonesian version of MMPI-2-RF RC Scales, namely Psychological Disorders. From the results of this study, users must be careful in interpreting RC Scales scores. This is because RC Scales cannot exclusively ascertain the structure in which a person experiences problem, with the exception of $\mathrm{RC} 2, \mathrm{RCd}$, and $\mathrm{RC} 9$ which seems to have more load on mood problems. For future studies, we suggest a study of other scales or sub-scales of MMPI-2-RF itself. Data from other scales can help users (psychiatrist or clinical psychologist) in obtaining a more comprehensive picture of the patient's problems. For further research related to factor analysis on RC Scales, we suggest that the analysis be carried out on the dimensions of the item, not on the sub-scales. This is important to avoid the number of variables being too few for an EFA.

\section{References}

Agus, D. (2009). Psikopatologi dasar di dalam memahami tanda dan gejala dari suatu gangguan jiwa (Basic psychopathology in understanding sign and symptoms of mental disorders). Jakarta: Departemen Ilmu Kedokteran Jiwa dan Perilaku Fakultas Kedokteran Universitas Katolik Indonesia Atma Jaya.

APA. (2013). American Psychiatric Association: Diagnostic and Statistical Manual on Mental Disorder (Fifth ed.). Arlington, VA: American Psychiatric Association.

Ayuningtyas, A. C. (2004). Adaptasi MMPI-2 untuk Aplikasi Indonesia: Analisis Psikometrik pada Subskala Low Self Esteem, Social Discomfort, dan Work Interference dalam Content Scales (Adaptation of MMPI-2 for Indonesian: Psychometric analysis on Low Self Esteem, Social Discomfort). (Undergraduate Thesis), Universitas Katolik Indonesia Atma Jaya, Jakarta.

Ben-Porath, Y. S., \& Tellegen, A. (2008). MMPI-2RF: Manual for administration, scoring and interpretation. Minneapolis: University of Minnesota Press.

Ben-Porath, Y. S., \& Tellegen, A. (2018). Minnesota Multiphasic Personality Inventory-2Restructured Form ${ }^{\circledR}$ (MMPI-2-RF®). Retrieved June 7, 2018, from https://www.pearsonclinical.com/products/100000631/minnesota-multiphasicpersonality-inventory-2-rf-mmpi-2-rf.html

Cohen, R. J., \& Swerdlik, M. E. (2018). Psychological testing and assessment: An introduction to tests and measurement (9th ed.). New York: McGraw-Hill International Edition.

Fields, A. (2009). Discovering statistics using SPSS (3rd ed.). London: SAGE Publications Ltd.

Halim, M. S. (2004). Adaptation and validation of the Indonesian version of MMPI-2: A preliminary report. Beijing: Paper presented on the XXVIII International Congress of Psychology.

Halim, M. S. (2012). The Indonesian version of MMPI-2-RF: A psychometric evaluation (I). Amsterdam: Paper presented in the 8th Conference of International Test Commission. 
Harkuspi, I. E. (2004). Adaptasi MMPI-2 untuk aplikasi Indonesia: Analisis psikometrik pada subskala Anxiety dan Depression dalam Content Scales (Adaptation of MMPI2 for Indonesian: Psychometric analysis on Anxiety and Depression subscales of Content Scales). (Undergraduate Thesis), Universitas Katolik Indonesia Atma Jaya, Jakarta.

Hoeksema, S. N. (2014). Abnormal psychology (6th ed.). New York: McGraw-Hill International Edition.

Hoelzle, J. B., \& Meyer, G. J. (2008). The factor structure of the MMPI-2 restructured clinical (RC) scales. Journal of Personality Assessment, 90(5), 443-455. https://doi.org/10.1080/00223890802248711

Howitt, D., \& Cramer, D. (2011). Introduction to research methods in psychology (3rd ed.). Essex: Pearson Education Limited.

Ingram, P. B., Kelso, K. M., \& McCord, D. M. (2011). Empirical correlates and expanded interpretation of the MMPI-2-RF restructured clinical scale 3 (Cynicism). Assessment, 18(1), 95-101. https://doi.org/10.1177/1073191110388147

International Test Commission. (2016). The ITC guidelines for translating and adapting tests (2nd ed.). Retrieved from www.InTestCom.org

Nastasya, P. (2004). Adaptasi MMPI-2 untuk aplikasi Indonesia: Analisis psikometrik personality psychopathology five scales (Adaptation of MMPI-2 for Indonesian: Psychometric analysis personality psychopathology five scales). (Undergraduate Thesis), Universitas Katolik Indonesia Atma Jaya, Jakarta.

Pomerantz, A. M. (2016). Clinical psychology: Science, practice, and culture (4th ed.). California: SAGE Publications, Inc.

Simms, L. J., Casillas, A., Clark, L. A., Watson, D., \& Doebbeling, B. N. (2005). Psychometric evaluation of the restructured clinical scales of the MMPI-2. Psychological Assessment, Vol. 17, pp. 345-358. https://doi.org/10.1037/10403590.17.3.345

Subandi, M. A., \& Good, B. J. (2018). Shame as a cultural index of illness and recovery from psychotic illness in Java. Asian Journal of Psychiatry, 34, 33-37. https://doi.org/10.1016/j.ajp.2018.04.005

Tellegen, A., \& Ben-Porath, Y. S. (2008). Minnesota Multiphasic Personality Inventory-2 Restructured Form: Technical manual. Minneapolis: University of Minnesota Press.

Van Der Heijden, P. T., Egger, J. I. M., \& Derksen, J. J. L. (2010). Comparability of scores on the MMPI-2-RF scales generated with the MMPI-2 and MMPI-2-RF booklets. Journal of Personality Assessment, 92(3), 254-259. https://doi.org/10.1080/00223891003670208

Yuliani. (2004). Adaptasi MMPI-2 untuk aplikasi di Indonesia: Analisis psikometrik pada Clinical Scales, yaitu subskala Hypochondriasis, Depression, Hysteria, dan Psychasthenia (Adaptation of MMPI-2 for Indonesian: Psychometric analysis on Clinical Scales, Hypocondriasis). (Undergraduate Thesis), Universitas Katolik Indonesia Atma Jaya, Jakarta. 